\title{
Relações Alteradas - Ideias Suruwaha sobre Animais e Caça ${ }^{1}$
}

\author{
Miguel Aparicio \\ Universidade Federal do Rio de Janeiro, RJ, Brasil \\ E-mail:mgl.aparicio@gmail.com
}




\section{Resumo}

No mundo em transformação que os Suruwaha do vale do rio Purus concebem, os animais são ex-humanos, a partir de metamorfoses originadas em conflitos de socialidade. O artigo analisa as ideias suruwaha sobre animais e caça, inscritas nas narrativas e nas práticas venatórias deste grupo indígena que habita nas terras-firmes do interflúvio Purus-Juruá. A caça, como uma das atividades de excelência para os Suruwaha, é concebida a partir de experiências de tensão entre os homens, os animais e seus donos. As relações com os animais oscilam entre movimentos de predação e de adoção, que fundam de modo paradoxal concepções de adoção predatória e de contrapredação nos humanos.

Palavras-chave: Suruwaha. Caça. Amazônia. Relação humano/animal.

\section{Abstract}

In the transformational world that Suruwaha from Purus valley conceive, animals are ex-human, because of metamorphoses originated in conflicts of sociality. The paper analyzes the Suruwaha ideas about animals and hunting, inscribed in the narratives and practices of this indigenous group inhabiting the lands of the Purus-Juruá interfluve. Hunting, as one of the activities par excellence for Suruwaha, is conceived from the experiences of tension between people, animals and their masters. Relations with animals oscillate between movements of predation and adoption, founding paradoxically conceptions of predatory adoption and counter-predation in human.

Keywords: Suruwaha. Hunting. Amazonia. Human/animal relationship. 


\section{Introdução}

Os animais eram pessoas, jadawa, que num momento viveram transformações (jahuruwa) que lhes deram a aparência peculiar de cada espécie. Os mitos dos Suruwaha ${ }^{2}$ sobre antas, queixadas, iraras, sucurijus, etc. insistem recorrentemente nessa dinâmica transformacional das pessoas que "viraram animais" - tornando-se para os humanos jadawakyba, "ex-pessoas". A passagem aparece marcada pelo conflito: a raiva de Buraku, ao receber a notícia da morte de seu pai, faz com que ele se transforme em pirarucu; os queixadas resolvem matar suas esposas, que fizeram sexo com as ariranhas, e experimentam a alteração dos seus corpos; a anta fracassa na sua tentativa de transladar-se ao patamar celeste; os conflitos de feitiçaria entre Baka e seu irmão Tiwiju derivam na transformação do primeiro em jacaré-açu... Dá a impressão que, para os Suruwaha, há uma condição originária própria de humanos ${ }^{3}$ que, alterada pela quebra da socialidade (as transformações sempre aparecem como decorrência de conflitos diversos), dá origem a um novo estado de humanos-transformados-em-animais, ou seja: é produzida a descontinuidade das espécies. Essa percepção da passagem de humanos a animais vinculada a conflitos de socialidade está também presente em outros cenários amazônicos; assim, é possível detectar semelhanças entre a ideia suruwaha de transformação (jahuruwa) e a ideia de ayawa nos Enawene-Nawe:

[...] o que está em questão neste contexto ontológico da socialidade é a diferença e não a semelhança cultural entre humanos e não-humanos, uma vez que esta é o fundo comum de ambos. Um mínimo que seja de antisociabilidade caracteriza a diferença, que pode ser para 
mais ou para menos na gradação de sociabilidade geral. (Mendes dos Santos 2006, p. 117)

Essa dinâmica transformacional se dá como transformação nos corpos, e as narrativas revelam uma lógica das qualidades sensíveis como âmbito das metamorfoses (por exemplo, as pessoas que correm pela floresta e atravessam áreas de palmeiras com espinhos se transformam em queixadas; o caçador que se nega a assar a carne no moquém e acaba comendo carne podre se transforma em urubu). Seres originariamente semelhantes - pela sua socialidade harmoniosa - derivam em sujeitos de dessemelhança - pela socialidade alterada no conflito. Transformação de perspectivas, transformação de corpos.

\section{Narrativas de Transformação}

Parece pertinente afirmar que há um principio cosmopolítico como fundamento, que move a "[...] ordenar e constituir as relações entre os distintos seres do Cosmos por meio da diferença" (Gonçalves 2001, p. 380). Os relatos a seguir ${ }^{4}$ expressam essas transformações, que conectam os diversos agentes do mundo. Como chave de leitura, é oportuno levar em conta a advertência de Gow (2001, p. 193): “Ao tentar obter explicações exegéticas dos mitos, uma das primeiras lições que aprendi foi que era inútil procurar descobrir se um determinado personagem era um ser humano, um animal ou um espírito". De fato, as ideias sobre os animais que as narrativas suruwaha manifestam expressam ideias sobre o mundo relacional ("cultural") dos humanos: “[...] muitos dos mitos etiológicos indígenas narram menos uma origem-gênese do que o modo pelo qual atributos que irão caracterizar a sociabilidade humana foram apropriados de animais". (Fausto, 2008, p. 338)

\subsection{O Pirarucu}

O pirarucu (Buraku) é uma pessoa (jadawa), morava numa casa como a nossa. Buraku estava na sua casa, sua nora menstruou. Estava menstruada e pediram que fosse à beira da casa e ficasse lá. “Vou 
caçar", disse o pirarucu. Saiu sozinho pelo rio, saiu na canoa, a sua canoa mergulhou na água. Os peixes iam transformar-se, na casa dos espíritos dos peixes (aba karuji iri uda) as pessoas iam transformar-se em peixes. As pessoas não caçavam, não matavam bichos, fizeram então uma peteca com palha de milho. Havia muitos peixes, eram pessoas. O peixe que se chama matrinxã era uma pessoa, o peixe que se chama acará era uma pessoa, o peixe que se chama piau era uma pessoa, o peixe que se chama traíra era uma pessoa: todos os peixes eram pessoas.

Buraku tinha levado a canoa, seu pai conhecia a canoa de Buraku. O pai morava no alto. De repente, caiu uma larva de mosca-varejeira, Buraku a pegou e olhou. A larva falou, ela disse a Buraku: "Eu estava na terra do teu pai" ${ }^{\prime}$. Buraku ficou com raiva, deitou durante a noite e de manhã foi embora [à casa do pai], acompanhado pelo esquilo. O esquilo era uma pessoa. Levou consigo a sua zarabatana, que era comprida. Ele disse: "o pai de Buraku morreu, as pessoas morreram".

\subsection{Os Queixadas}

Os queixadas eram pessoas, moravam numa casa como a nossa, eles derrubavam roçados no verão. As suas esposas pilavam milho à beira do igarapé e tomavam banho. As esposas estavam sozinhas à beira do igarapé, quando chegaram as ariranhas. As ariranhas também eram pessoas. As mulheres queriam pegar peixe, mas não conseguiam. As ariranhas transavam com as mulheres-queixadas e pegavam peixe para elas, deixavam os peixes na praia do igarapé. As mulheres-queixadas tomavam banho, as ariranhas se aproximavam debaixo d'água, transavam com elas e lhes davam peixe. Os coraçôes dos homens-queixadas pensaram assim: "Como é que as mulheres conseguem pegar tanto peixe? Vá lá ver o que está acontecendo". A cobra-surradeira foi ao local, ficou observando de um galho, e viu que os homens-ariranhas faziam sexo com as mulheres-queixadas. A cobra-surradeira viu o que estava acontecendo, se jogou na água, bateu com seu corpo nas ariranhas, que fugiram depressa. As mulheres riram, mas ao ver que a cobra-surradeira tinha visto o acontecido, disseram: "Agora ela saiu 
daqui a vai contar tudo aos homens-queixadas!". A cobra-surradeira foi embora e contou aos maridos o que ela tinha visto. Os homensqueixadas, furiosos, disseram: "Chega, vamos lá!". E flecharam todas as mulheres-queixadas. Os homens-queixadas mataram todas as esposas-queixadas.

Depois de um tempo, os homens-queixadas estavam desgostosos com a falta de mulheres. As mulheres-queixadas tinham sido mortas e não havia quem preparasse mandioca. A mandioca não ficava bem preparada, a mandioca ficava grudenta. Os homens-queixadas disseram a Jamuhawari, o caititu: "Chega, mata-nos a todos, acaba conosco!" E Jamuhawari atirou flechas em todos, até ficar ele sozinho. Depois, ele mesmo se flechou, correu, pegou os ossos dos queixadas e os esfregou com as suas mãos. Os queixadas saíram correndo pela mata, ficaram cheios de espinhos, seus corpos se encheram de espinhos e reviveram, transformados em queixadas. Jamuhawari olhou em volta e viu ossos, muitos ossos. Os corpos das mulheres-queixadas não tinham sido comidos, estavam apodrecendo. Juntou todos os ossos, os esfregou com as mãos, bateu os ossos no chão e disse: "Vão!" Então, as esposas saíram correndo, elas reviveram.

Buraku chegou e ouviu o barulho: "Aí estão os queixadas". Estava junto com o esquilo Juwaki. Juwaki carregava a sua zarabatana comprida, e Buraku lhe disse: "Vamos, dispare!" Ele andou, os queixadas estavam comendo cocos de joari, Juwaki também pegou coquinhos de joari, comeu e disse: "São gostosos!", e desistiu de atirar nos queixadas. Foi embora sem flechá-los, então o pirarucu o seguiu pelo igarapé, viu o esquilo colhendo e comendo frutas de joari e ficou com raiva. O esquilo subiu numa árvore, subiu no alto de uma árvore, e o pirarucu lhe disse: "Desça logo!" Então o pirarucu atirou a sua flecha, que espetou o esquilo no dorso. A flecha se transformou no rabo do esquilo. ${ }^{6}$ O pirarucu disse: "Chega, já vou".

Buraku saiu na sua canoa, até chegar ao lugar do seu pai, e viu que não havia mais pessoas. Todas as pessoas tinham sumido, com exceção da nora. A nora estava na beira da casa, havia pássaros, havia mutuns. Buraku chegou perto e disse: "O que aconteceu? Por que todas as pessoas desapareceram?" 
A nora disse: "Foi devido ao que as ariranhas fizeram". O pirarucu ficou irritado. Então chegou Biruwa, ela era uma mulher-juriti e conversou sem parar, conversou muito, conversou muito com o pirarucu, e comeu um mutum que havia lá. Depois de comer o mutum, Biruwa teve diarreia e o pirarucu lhe disse: "Agora você tem diarreia e eu vou pegar a dor da diarreia!" Ela defecou dentro da canoa, defecou muito até que Buraku alagou a canoa para tirar a diarreia. Mas ela continuava defecando, e Buraku tinha que continuar alagando a canoa. Então Buraku pegou a Biruwa, esfregou suas mãos nela, assoprou e seu sopro a jogou no alto do galho de uma árvore: Buraku transformou Biruwa num juriti. "Eu fico aqui, você fica aí acima", disse Buraku a Biruwa.

Buraku foi embora até chegar à casa dos peixes, a casa dos espíritos dos peixes (aba karuji iri uda). Os peixes eram pessoas, gente como nós. Ao chegar, disse: "Lá não há mais pessoas". Os peixes ficaram com raiva, e pintaram seus corpos com pintura preta. Todos os peixes se pintaram, ficaram muito pintados, havia um igarapé, então as pessoas se transformaram em peixes. Buraku se transformou em pirarucu: "Lá acima não há mais gente, isso é muito ruim", ele disse. E pegou todos os ossos, pegou muitos ossos, esfregou suas mãos neles, os bateu, os lançou, e então os ossos se transformaram em macacos-cairaras. Os ossos das mulheres-queixadas se transformaram em macacos-cairaras. Foi assim que aconteceu.

\subsection{A Sucuriju}

A sucuriju era uma mulher, contam. Transformou-se porque ela era xamã, ela era uma mulher xamã. Havia muito peixe para os homens. Ela chegou, viu o peixe e disse: “Que bom!" Pegou os peixes, colocou seu feitiço neles e foi embora. Chegou a casa, cozinhou os peixes, os comeu e depois sentiu muita sede. Bebeu água, bebeu muita água, mas não ficou saciada. Saiu da casa e se jogou na água, mergulhou e se transformou em sucuriju.

Chegou Wakabi. A sucuriju estava à beira do igarapé, tinha muitas matrinxãs. Wakabi as viu, foi correndo a casa, quando chegou a casa disse: "Vamos flechar matrinxãs!" Mas não conseguiu flechá-las, 
a sucuriju segurava as flechas. Quando Wakabi atirava, a sucuriju segurava as flechas com a mão. Wakabi estava perto da sucuriju, a sucuriju o agarrou e o engoliu. Wakabi criava um macaco zogue-zogue, que a sucuriju engoliu também, só a cabeça ficou de fora. Porém, Wakabi não morreu no ventre da sucuriju. Enquanto a sucuriju dormia, Wakabi disse: "Vou sair daqui!" Mas não conseguia sair. Depois a sucuriju dormiu profundamente, Wakabi conseguiu sair. Saiu pela boca da sucuriju, caminhou até a casa. Então, ao acordar e perceber que Wakabi tinha escapado, a xamã sucuriju contou ao seu marido o acontecido. O marido disse: "Vai lá, as pessoas estão cantando, vai lá". Havia muitas pessoas cantando, a sucuriju se aproximou, avançou pelo caminho, havia muitos jovens, as pessoas dançavam. A sucuriju chegou enquanto as pessoas estavam dançando. As pessoas conseguiram pegar a sucuriju e carregá-la, as pessoas todas carregaram a sucuriju e a amarraram, ela era muito pesada. De manhã cedo mataram o marido da sucuriju. Mataram o marido, mataram a esposa, chuparam os corpos das sucurijus e se transformaram em pessoas. O povo de Wakabi se transformou em pessoas, mataram a sucuriju e se transformaram em pessoas. Todos estavam bem alimentados, prepararam a mandioca e comeram a sucuriju.

\subsection{Baka $^{7}$}

Baka era xamã, havia muitos xamãs naquele tempo. Kabani era xamã, Jama era xamã. Tiwiju tinha uma esposa, Baka estava com raiva e dizia: "Eu não tenho esposa". Baka sentia raiva. As pessoas estavam inalando tabaco, Tiwiju bebeu água, Baka chegou, ele sentia dor nas unhas dos dedos, e colocou feitiço em Tiwiju. Tiwiju sentiu dor de repente. Ele disse a sua esposa: "Acenda o fogo". As pessoas pegaram lenha e acenderam o fogo, acenderam uma fogueira grande. De manhã Baka saiu para caçar. A mãe de Baka tinha pegado peixe e ia prepará-lo para cozinhar. Tiwiju sentia dor e disse: "Joguem-me no fogo". Sua esposa o colocou no fogo. As pessoas observavam os olhos de Tiwiju, ele disse: "Estou quente". E pediu que o espetassem e o jogassem no igarapé. As pessoas espetaram o corpo de Tiwiju e o jogaram na água, 
sua esposa o jogou no igarapé. As águas começaram a secar, as água desceram. Baka tinha ido embora. Viu que os rios estavam vazando. Baka se surpreendeu, pegou peixe, havia muitas piabas, e depois foi embora. Num outro igarapé, viu que havia piaus e os pegou. Depois, em outro igarapé, jogou os piaus fora, viu que havia matrinxãs e os pegou. Carregou um cesto grande com os peixes e chegou a casa, sua mãe estava cozinhando.

Sua mãe cozinhou os peixes e Baka comeu. Sentiu muita sede, bebeu toda a água do pote, bebeu muita água até acabar com a água dos potes. Então chegou Jatanamary, irmão mais velho de Baka e de Tiwiju. Baka disse: "Sente aqui, Jatanamary". Então as pessoas prepararam flechas, prepararam muitas e muitas flechas e Baka as disparava, todas elas ficaram na praia. Disparava as flechas e buscava Tiwiju seguindo a direção delas. Atirava uma flecha, e esta caia na praia. Atirava outra flecha, e caia na praia. Atirava mais uma, e também caia na praia, até que acabaram todas as flechas. Voltou a casa, preparou mais flechas. As disparou de novo, disparou todas as flechas, e depois saiu.

Baka sentiu sede, não havia mais água, ele disse: "Vou subir no céu, lá no alto tem água". Mas as águas do céu também tinham secado, e havia mato. Lambeu a pouca água que encontrava, sentia sede, Baka já não conseguia caminhar, o sol estava quente, não bebia água e morreu. Baka, ao morrer, se transformou em jacaré-açu.

Jatanamary atirou as flechas, atirou flechas e flechas e flechas, até que as flechas iam acabar. "Tenho poucas flechas, vou lançar bem longe as que tenho ainda", ele disse. Disparou e disse: 'Voem longe, flechas!" Tiwiju estava no igarapé, havia água, mas ele não conseguia vê-lo. Atirou e flechou matrinxãs. Jatanamary escutou um barulho parecido ao trovão, era o barulho das matrinxãs. Então ele subiu. As pessoas da casa estavam na praia e lhe disseram: "Vá pegar as matrinxãs". As mulheres apanharam as matrinxãs e as cozinharam. As pessoas olharam, olharam longe e viram Jatanamary. As pessoas o viram, chegaram onde ele estava, lá longe tinha água, as águas tinham subido, e havia muitas canoas. Saíram correndo, embarcaram nas canoas, a mãe ouviu um barulho parecido ao dos trovoes. “Ouçam! Lá está o meu filho!", disse a mãe. Chorou, chorou, a mãe escutou o filho, 
chegaram. Tiwiju estava desmaiado. Sua esposa deu-lhe um alimento doce, semelhante à cana. Ele tomou e começou a reanimar-se aos poucos, como era jovem e forte ele se recuperou e depois comeu peixe.

As pessoas embarcaram nas canoas, eram muitas canoas, as pessoas subiram e viram as flechas que tinham sido lançadas, viram e conheceram as flechas que tinham sido disparadas. "Lá está Tiwiju", disseram. E depois: "A canoa dele não está aqui, está lá". A sua mãe o pegou, o colocou na canoa. Depois foram na casa de Tiwiju, que fica ao leste.

\subsection{As Serpentes}

Kuwiri, a serpente, era uma pessoa adulta, tinha suas flechas. Ele preparava veneno, colocava o veneno nas flechas e os jovens saiam para caçar. Kuwiri tocava as flechas, tocava e tocava as flechas, e o seu veneno as impregnava. Um dia a serpente saiu e mordeu uma pessoa. A pessoa foi mordida, chegou a casa, mas não morreu. A pessoa tinha seu espírito karuji, a serpente pegou o karuji da pessoa e o comeu. Não caçava, ninguém via suas flechas, ele preparava o veneno, o guardava, as pessoas o viam saindo, ele tocava as flechas, que ficavam envenenadas e se transformavam em serpente. Sim, Kuwiri preparava o veneno, tocava as flechas, as lambuzava com veneno, e as flechas se transformavam em serpente.

Depois de alguns dias Kuwiri, estava com a sua filha, com o marido da filha e com o filho destes. Kuwiri tocou suas flechas, o veneno saiu e mordeu o neto. Ele ficou quase morto, o levaram para casa, estava desmaiado, o pai pegou nele, estendeu seu corpo no chão, cavou o túmulo, mas depois de uns dias Kuwiri foi embora. Saiu correndo, penetrou debaixo da terra, chegou ao entardecer, à noite foi comer. O genro de Kuwiri tinha muita raiva pelo que tinha acontecido com seu filho. Ele viu a sua esposa e o seu genro comendo e perguntou: “O que vocês estão comendo?". A mulher disse: "Estou comendo o meu pai". Mas em realidade estava comendo o seu filho. O marido dela [genro de Kuwiri] sentiu o cheiro e percebeu que estavam comendo o seu filho: "Vocês estão comendo meu filho!" E não conseguiu dor- 
mir durante a noite. De manhã pilou tabaco, pilou muito tabaco e se transformou em pessoa. Ele tinha feitiço, assoprou tabaco, assoprou muito tabaco no seu sogro, pois seu filho tinha morrido por causa do veneno de Kuwiri. Kuwiri guardava seus bichos de estimação num cestinho, e guardou nele cobras com veneno. Havia um fogo, a sua filha o pegou, sentou ao lado, o fogo de Kuwiri estava forte, ela saiu correndo e se transformou em serpente.

No céu está o caminho do espírito da serpente. Ela viu o menino e disse: "Vem cá!". Está no céu, as pessoas o chamam de caminho das serpentes. Nele transitam os espíritos das serpentes (kuwiri karuji). Por ele caminham também as presas das serpentes ${ }^{8}$.

\section{Caça e Ritual no Zawada}

Essa dinâmica de produção de alteridades que a etiologia descrita nas narrativas suruwaha manifesta é atualizada no âmbito e na experiência da caça, onde reaparece o conflito de socialidade entre os humanos e os animais transformados em presas (bahi). Há duas principais modalidades de prática de caça entre os Suruwaha (além da caçada individual, cotidiana entre os homens): o kazabu e o zawada. No kazabu é organizado um acampamento de tapiris familiares em áreas distantes da zona residencial das malocas, e há sempre um dono anidawa que o promove. Mobiliza homens, mulheres e crianças - pode ser praticado por poucas famílias ou por todas as famílias da aldeia. Os grandes kazabu costumam serem praticados nos meses de maio e junho, ao final do inverno, em lugares pouco frequentados durante o resto do ano e onde, em consequência, as caçadas poderão contar com bons resultados.

Porém, a caçada coletiva mais expressiva para os Suruwaha é o zawada, na qual participam exclusivamente os homens. O zawada pode reunir um grupo pequeno de caçadores, mas normalmente, uma vez ao ano, um dos homens de maior prestígio organiza um zawada que congrega todos os caçadores. Ele é o dono, o anidawa da caçada. Os Suruwaha atribuem liderança as pessoas que têm karuji forte. As pessoas, os animais e as plantas são animados pelo seu karuji, expressão 
com muita proximidade ao termo latim anima e que expressa "vitalidade" em dois sentidos convergentes: por um lado, significa a força vital, o princípio animador de esse ser: o "espírito das plantas" (aha karuji) que sustenta o seu crescimento, o "espírito das flechas" (tyby karuji) que efetiva a agência das mesmas, etc. Por outro lado, karuji expressa a vitalidade da pessoa na sua rede relacional, 9 o "carisma" que a torna proativa, líder, animadora da vida coletiva: os bons anidawa (os donos de caçadas e pescarias coletivas, ou de roçados muito produtivos), pela sua capacidade de impulsionar a vida do grupo, pela sua magnanimidade, eles têm karuji forte. ${ }^{10}$

O grupo de caçadores se dirige a um lugar da floresta distante dois ou três dias das casas; lá montam um acampamento a partir do qual se realizarão as caçadas durante uma semana ou mais dias. A carne dos animais caçados se conserva nos moquéns; durante os dias da caçada coletiva os homens se alimentam apenas de miúdos, vísceras, pequenos animais, pescado e gordura com mandioca: a carne das antas, queixadas, caititus, macacos-barrigudos, pacas e veados é conservada para os rituais coletivos na aldeia. As festas de zawada são, do ponto de vista ritual, o momento mais denso do calendário suruwaha, e de forma ideal são oportunidade perfeita para o rito de sukwady hirikiari, iniciação masculina ${ }^{11}$, e inclusive para a realização de casamentos. Apresento aqui uma descrição de um zawada organizado por Hamy ${ }^{12}$ em maio de 1998, no qual tive oportunidade de participar.

\subsection{Preliminares do Zawada}

Os caçadores dos barreiros de Xubanza chegaram a casa. Entraram todos juntos na maloca com um ar severo e solene. Aparentemente ignoravam as pessoas presentes, principalmente as mulheres (mães, irmãs, esposas). Sentaram-se nas suas redes e inalaram tabaco: alguns solicitavam aos companheiros que lhes assoprassem fortes doses de rapé. Depois de um tempo de silêncio, em que se reconciliaram com os mestres-donos dos animais abatidos, começaram os habituais relatos da caçada, com toda a atenção dos que tínhamos permanecido na maloca. As mortes das duas antas abatidas por Mawaxu e Wahary 
foram descritas com profusão de detalhes. Queixadas, macacos e mutuns completavam o resultado da caçada, bahi. Durante os últimos dias, o grupo de caçadores tinha ido até o alto Riozinho, atravessando os roçados do Xubanza. O ambiente na casa estava animado. Hamy ofereceu o cesto de mandioca fermentada depositado no leito do igarapé Xindigiaru. Ele, com seu carisma, animava a todos a preparar a grande caçada deste inverno, a ser realizada brevemente.

Poucos dias depois, preparativos do zawada de Hamy no igarapé Jukihi, já iminente: todos os homens preparam suas armas de caça, e os cestos com a provisão de mandioca para os dias de acampamento em terra firme.

\subsection{Caçada no Igarapé Jukihi}

O zawada de Hamy teve início com o grupo de caçadores descendo o igarapé Jukihi nas canoas. Fomos remando todos juntos, num ambiente descontraído, parando para comer frutas na beira. No entardecer paramos para pescar e levantar um acampamento para o pernoite. No dia seguinte continuamos a descida, até um pequeno lago próximo à foz do Jukihi onde Hamy, dono da caçada (anidawa), resolveu levantar um acampamento, uda baza. Alguns foram pescar, outros ficaram organizando o acampamento e um grupo foi abrir uma picada no rumo do Riozinho, atravessando a várzea em direção montante. Kwakwai matou um caititu. No entardecer voltamos ao acampamento, já preparado. Todos os homens estavam presentes na caçada, com exceção de Kuxi, que tinha ficado para concluir a cobertura da maloca, em processo de reforma.

No primeiro dia da caçada, com o acampamento já estabelecido, Kwakwai foi ver um dos barreiros próximos à foz do Jukihi, do outro lado do Riozinho. Matou uma anta adulta, fêmea. Participei do grupo de carregadores que foi apanhá-la. Já tinham tocado a primeira buzina huriatini ${ }^{13}$ desta caçada. Ania rastejou outra anta num barreiro da várzea do Riozinho, nas proximidades do local onde Ainimuru estava caçando. No dia seguinte, Wahary abateu a terceira anta destes dias, numa picada aberta na beira oposta do rio, já próximo às cabeceiras 
do igarapé Jaxiru. As três antas foram entregues a Hamy, líder do zawada, que assume, em consequência, a função de nauhyru das peças prediletas ${ }^{14}$. Naquela mesma noite, Ikiji chegou dizendo que tinha encontrado um grupo de macacos-barrigudos (gaha), seguindo-os até o local onde iriam pernoitar. A estratégia já estava montada na técnica de caça suruwaha: ao amanhecer, bem cedo, todos foram armados com as zarabatanas; Kwakwai coordenou a movimentação dos caçadores. O cerco ao redor do grupo foi montado sigilosamente; após abaterem as primeiras vítimas, todos se espalharam para perseguir os macacos fugitivos. Foram abatidos mais de quarenta macacos.

Durante os dias de caçada, as mulheres cantavam, nas malocas, os wajumari noturnos. Preparavam-se assim para os rituais. Comentavase a possibilidade de celebrar a iniciação dos jovens Xagani, Kaurara, Aruazy e Tuhwawi. Daiahka, Kuni e Muru lideravam o canto ritual, correspondendo-se com as mais destacadas lideranças masculinas: seus respectivos esposos Xamtiria, Hamy e Kwakwai.

Depois de vários dias abatendo só peças menores (mutuns, macacos-prego, cairaras...), Kabuha encontrou uma trilha de queixadas. Chamou os caçadores com a buzina huriatini, reunindo um grupo de vinte pessoas. Após pouco mais de uma hora de caminhada na mata, ouviu-se o barulho inconfundível da vara. Advertiram nossa chegada e os caçadores iniciaram a perseguição; apenas quatro queixadas foram abatidos. Após 11 dias de expedição, os caçadores empreenderam o retorno a casa, subindo o igarapé Jukihi. De manhã todos acordaram cedo para preparar os cestos com a carne obtida, conservada durante os últimos dias nos moquéns. Durante a viagem nos surpreendeu uma forte ventania, que quebrava árvores e galhos na beira do igarapé. Aconteceu um acidente: um galho caiu na canoa de Axidibi, partiu-a e alagou com tudo. Felizmente ninguém ficou machucado. Os caçadores das outras canoas acudiram ao local do acidente, mergulharmos para recuperar os objetos afundados: armas, redes, os cestos com a carne. Continuamos remando até a maloca de Uhuzai; no dia seguinte, de manhã, os caçadores chegavam à caça de Kuxi, onde aconteceriam as celebrações do zawada. 


\subsection{Casa de Kuxi}

Dia de grande festa, em toda a sua solenidade. Kuxi e outros homens trabalham apressados para concluir a cobertura da casa, as mulheres assam a mandioca-puba nos alguidares, e as panelas novas, recém-confeccionadas pelas mulheres mais habilidosas ${ }^{15}$, cozinham as antas e queixadas da caçada. A entrada dos caçadores na casa foi solene: todos em fileira, Hamy o primeiro, os corpos pintados de urucum, a expressão dos rostos com um ar rigoroso e árduo, os cestos de carne jogados com força no chão. Homens e mulheres mostram indiferença diante do fato do retorno; os caçadores se assopraram tabaco mutuamente, com veemência. Aos poucos as mulheres foram oferecer comida aos filhos e esposos, principalmente a cana que, depois de vários dias na mata, é um dos alimentos mais almejados. À noite os jovens cantaram o kawajumari, liderados por Uhuzai. O canto ritual se sucedeu durante várias noites, num dos momentos mais intensos do calendário suruwaha. De manhã Kabuha, Agunasihini e outros foram no igarapé Xindigiaru para preparar o transporte do volumoso cesto de mandioca-puba submersa na água, o agasi para a comida festiva. O cesto era pesado, não dava para transportá-lo inteiro como o rito pede, pois poderia quebrar. Os jovens Naru e Giani carregaram parte da massa em paneiros menores. O resto foi levado até a maloca conforme os padrões do rito: uma pessoa carrega-o nas costas com uma embira amarrada na cabeça, o resto dos homens acompanha ajudando e mantendo o equilíbrio da carga; tudo num clima de alegria, exibição de força e diversão. O cesto avançava com lentidão, cada carregador conseguia dar com denodado esforço quatro o cinco passos, revezando-se com outras pessoas. Os caçadores, após a tarefa desmedida, repuseram as forças com garapa de cana e pamonhas de milho. O dia seguinte amanheceu em clima de festa. Procuraram várias toras de lenha e acenderam uma grande coivara no local de Hamy. As mulheres, principalmente as viúvas e as parentes mais próximas a Hamy, passaram a manhã toda escaldando a mandioca-puba nos alguidares. Uma enorme panela, feita por Kuni, esposa do anidawa, cozinhava carne de anta. Alguns homens foram ao roçado próximo para pintar os corpos com urucum 
e com zamasaru, tintura preta feita com gordura de macaco, cinza e breu. À tarde colocaram folhas de bananeira no centro da casa, os homens iniciaram o banquete festivo. Enquanto um grupo retalhava os pedaços de carne para a distribuição, os demais iam comendo a caça com cuscuz de mandioca. No final, Hamy colocava as porções de carne e a mandioca nos alguidares de cada um: Kwakwai, Xamtiria, Kuxi. A escala social de prestígio aparecia com nitidez na sequencia da distribuição. À noite houve cantos kawajumari das mulheres: foi realmente espetacular. As mulheres com seus corpos pintados de urucum, com as tangas enfeitadas com penas de tucano e miçangas. Colares de dentes no pescoço a modo de chocalho marcavam o ritmo da dança. O canto foi prestigiado pelas mulheres adultas: Dimi, Iju, Kainaru, Wixkiawa, a quem acompanhavam as jovens e muitas meninas ainda pequenas. A dança foi entusiasta, prolongando-se até o amanhecer. Abraçadas ou em roda, em espiral ou em fileira, com as mãos no ombro da companheira, entoaram os cantos dos espíritos-cantores kurimia e dos karuji aprendidos dos xamãs. Os homens acompanhavam sentados em volta, conversando, cheirando tabaco ou chupando cana. Com os primeiros raios do sol, as mulheres saíram animadas, para tomar banho no igarapé Xindigiaru. Após a festa e os cantos noturnos, o dia amanheceu num clima muito tranquilo. No igarapé, um grupo de jovens esfregava no braço talos de planta com formigas kirumaji. A planta produz uma reação alérgica, que se junta à dor causada pelas ferroadas das formigas; com isso eles conseguirão que os animais flechados não escapem e o poder do veneno kaiximiani seja mais rápido e seguro. Assim me contaram Kawakani, Wahidini e Gianzubuni.

Nesse dia, Kuxi finalmente terminou a cobertura de caranaí da maloca. Muitos têm ajudado no acabamento da casa. Há dúvidas sobre se acontecerá ou não o rito de iniciação dos adolescentes Xagani, Aruazy, Kaurara e Tuhwawi; parece que Kwakwai, pai de Xagani e um dos melhores caçadores, duvida sobre a oportunidade do momento. No entardecer, Mawaxu quebrou a harmonia da maloca, destruindo arco e flechas, jogando fora a paina das setas da sua zarabatana, pisando uma panela e saindo para tomar timbó. ${ }^{16}$ Giani impediu a tentativa de envenenamento. O motivo foi uma discussão entre Mawaxu e sua 
esposa, Abi. Mawaxu voltou para casa, permaneceu sério e silencioso na sua rede, depois de ter arrancado alguns fios da mesma. Após o acontecido, os homens foram enfeitar-se com folhas de buduwa, a planta dos espíritos-cantores. Os homens iniciaram o canto rodando no terreiro central, até a madrugada. Hinijai dirigiu o canto, que foi melódico, pausado. Dessa vez, a festa não se prolongou até o amanhecer.

Dois dias depois aconteceu a segunda distribuição da carne das antas, queixadas e macacos-barrigudos. Foi interrompida por um falso alarme de queixadas na capoeira próxima. No retorno dos caçadores, Xidiaru tomou timbó, demorou algumas horas em recuperar-se. Ninguém prestou muita atenção, nem sequer as mulheres mais próximas; não parecia tratar-se de uma tentativa fatal. No fim do dia todos se reuniram com as suas respectivas famílias para jantar o último bahi da caçada. Os jovens foram buscar folhas de buduwa e embiras de tibari para ornamentar-se na dança noturna. Kwakwai e outros ficaram comigo, inalando tabaco. Era noite de canto kawajumari. Já passada a meia-noite, Axa, Gamuki e Uhuzai reuniram-se no centro começando a dança e convidando aos homens. A lua minguante já tinha saído, era noite de friagem. Incorporei-me ao pequeno grupo que, aos poucos, foi crescendo: Wahidini, Udy, Kuzari, Kabuha, o pequeno Zugusuwi, Kwakwai, Giani, Axidibi, Kawakani e eu dançávamos no centro da casa. Kuzari e Kawakani levavam nos ombros um arco de caça, enfeitados com o cocar de tibari e as saias de buduwa. Uhuzai e Axa dirigiram o canto; mais tarde foi Kwakwai quem liderou, durante a maior parte da madrugada. O kawajumari começou cantando ao sol nascente e aos espíritos da floresta e das plantas: o espírito da munguba (mahuwa karuji), o espírito do algodão (waby karuji), o espírito da bananeira (xari karuji), os espíritos subterrâneos (adabuhwa zamakusa), o espírito do açaí (harami karuji), os espíritos-cantores (kurimia), os povos inimigos (juma), os espíritos das frutas silvestres, a memória da ancestral Aniji, a árvore de taquari, os estrangeiros waduna. Com a dança do karuru chegamos ao amanhecer: todos nos abraçamos pelos cotovelos, avançando para frente com força, e retrocedendo devagar para depois avançar de novo, e assim sucessivamente. De manhã, Kwakwai convidou a todos para o rito dos gaha tymyri ${ }^{17}$. Foram buscar palhas de bacaba para enfeitar-se: 
amarraram as folhas nos braços, tórax, pernas, fizeram um cocar e uma borduna enfeitada com folhas de caranaí. O rumor imitava os macacos escondidos nas brenhas da mata. Fomos rumo à maloca imitando o grito dos macacos-barrigudos. Dançamos no terreiro central, todos esperavam o começo da luta. Começaram Udy e Jawanka. Gamuki, que permanecia deitado na sua rede, veio para aceitar o desafio. Lutou com Udy. Sucessivas lutas se desenvolveram com a participação e entusiasmo de todos. Com o rito dos macacos-barrigudos concluía a festa que se prolongou desde o entardecer anterior.

Finalmente não haveria ritos de iniciação dos adolescentes, Kwakwai preferiu que seu filho recebesse o suspensório peniano na sua própria casa, em outra ocasião. No próximo mês começará a derrubada dos novos roçados: Kwakwai está pensando em mudar de novo para o igarapé Kwariha, Hamy quer concluir sua casa nova e ampliar a roça do morro, e Wahary projeta casa e plantações novas no igarapé Ihkiahini, seu local preferido.

\section{A Tensão do Caçador}

Se esta modalidade de caçada constitui a atividade venatória preferencial dos Suruwaha, o cotidiano está permeado, com maior frequência, pela caçadas individuais de um único dia, ou por expedições de caça de pequenos grupos - os zawada ahaidini, "caçadas-filhas". Essas caçadas normalmente são realizadas percorrendo picadas transitadas habitualmente, e que partem da área residencial, até o momento em que a trilha dos animais procurados ou o roteiro de bacias hidrográficas menores vai marcando o itinerário de caça. Participei com frequência destes zawada ahaidini, com grupos de poucos caçadores equipados com o mínimo possível: arco, flechas e zarabatana, rede, faca, um pequeno cesto com mandioca e a brasa (transportada por algum adolescente que acompanha os caçadores adultos) necessária para garantir o fogo durante um trekking que se prolonga durante vários dias, num roteiro marcado pelos vestígios das presas potenciais. Não existe para os Suruwaha um termo específico que designe a atividade de caça: o termo utilizado é zamagawari, que significa propriamente "andar pela 
mata"18. A caminhada contínua durante horas e horas segue atenta aos rastros dos animais, de preferência as antas, os queixadas e os macacos-barrigudos. Para os Suruwaha não há, contudo, restrições de caça $^{19}$, a grande maioria dos animais terrestres - assim como das aves ou dos macacos - pode ser alvo das flechas ou da zarabatana do caçador.

O mito das serpentes apresentado anteriormente expressou o movimento de metamorfose das flechas-cobras. O poder de predação do caçador está no veneno das suas flechas e das setas da sua zarabatana: no kaiximiani - termo idêntico ao do veneno das cobras. Há, neste sentido, semelhanças com a concepção dos vizinhos Deni ${ }^{20}$. Para estes, o que os humanos veem como cobra é, para as cobras, o seu arco. Os dentes das cobras são, para as cobras, as suas flechas, sendo que cada tipo de cobra é um tipo de flecha, com determinado tipo de veneno. "Há cobras que são iha (o veneno de caça), há outras que são hadu (tabocas venenosas), e outras que são apenas cacetes sem veneno (as cobras que não têm veneno). As cobras (que nós vemos) são as armas da cobra que os xamãs deni conseguem ver". ${ }^{21}$ Segundo os Suruwaha, Kaiximiani era o nome do ancestral que se transformou no cipó com o qual se produz o curare das flechas de caça. Um dia Kaiximiani bateu acidentalmente com o cotovelo ${ }^{22}$ na cabeça de um menino, que logo depois ficou doente e morreu. O pai do menino ficou com raiva, pegou um pau e bateu em Kaiximiani, que se transformou em cipó. O curare das flechas e das setas da zarabatana é elaborado a partir dos cipós kaiximiani e xihixihi. A casca da trepadeira kaiximiani e o próprio cipó xihixihi são triturados num pilão específico, o kaiximiani kaby. A mistura de ambos, já pilados, é colocada num funil feito com folha de bananeira, com uma paina no seu interior que funciona como filtro. Aos poucos despejam água com a boca, lavando o sumo e coando-o: o veneno se acumula na vasilha kaiximiani dukuni. O recipiente é aquecido num fogo com abundante brasa. A pessoa fica mexendo o conteúdo com um pincel de pelos de caititu, espalhando a pasta pelas paredes da vasilha. O sumo vai adensando e produzindo uma espuma que, quando alcança o ponto ideal, é passada na ponta das flechas e dos dardos. O veneno será novamente aquecido periodicamente, para manter sua eficácia letal com os animais. Para os 
Suruwaha, oxihixihi age como macho e o kaiximiani como fêmea. Cada cipó kaiximiani que se encontra na terra firme pertence a um caçador, e se transmite de geração em geração. Os jovens são minuciosamente treinados pelos adultos para obterem um curare de qualidade, eficaz para abater as presas nas caçadas.

A obtenção da presa, bahi, provoca uma reação contida no caçador. Sempre me chamou a atenção a atitude do caçador ao chegar a casa: silencioso, seu rosto expressa uma sensação tensa, com total ausência de comemoração ou estridência. Com ar grave, ele se dirige ao seu lugar na maloca, coloca no chão o cesto que contém apenas as vísceras do animal abatido e se dispõe a inalar uma quantidade significativa de tabaco. Sua atitude nesses momentos indica mais conflito do que satisfação ou alegria pelo sucesso da caçada. As pessoas comentam discretamente a sua chegada e observam os sinais que podem apontar o tipo de animal que foi obtido. O caçador experimenta o lado perigoso, predatório da caça: parece estar imerso em um clima de tensão com o dono, anidawa, da sua presa. ${ }^{23} \mathrm{O}$ âmbito dos anidawa das presas do caçador fala do limiar arriscado que conecta humanos e não humanos, e no qual a morte do animal põe em evidência uma relação intensa, alterada (Kohn, 2013, p. 218). Em conflito com o "mestre-dono" do animal, o caçador suruwaha evita qualquer relação de domínio sobre a sua presa, e nomeia um nauhyru - a pessoa que será de fato responsável de buscar o animal abatido na floresta, carregar a cabeça do mesmo (as outras partes serão carregadas por um grupo de acompanhantes) e organizar o corte e preparo da carne, já na casa. O ambiente paulatinamente vai ficando mais distendido, e as pessoas, circunspectas, começam a fazer perguntas sobre o acontecido: o local e horário da captura, o sexo e idade da presa, a distância do disparo, a parte do corpo atingida pela flecha. Com cordialidade e empolgação crescente, o protagonista da caçada empreende um relato pormenorizado e detalhado da sua ação, com emoção patente e, inclusive, com pitadas inteligentes de humor ao conversar. Na sequência, o nauhyru, dono, carregador e cozinheiro do animal, organiza para o mesmo dia ou para a jornada seguinte o grupo de pessoas que irá apanhar a presa. Raramente o caçador retorna ao local do abate: seu relato carregado de informações e detalhes 
bastará para que o grupo caminhe durante horas e horas na floresta, até chegar ao local exato onde está o animal abatido.

Contrasta o silêncio inicial e tenso que o caçador demonstra, com a eloquência e profusão de detalhes com que ele descreve posteriormente as circunstâncias da caçada. De fato, o relato do caçador se desenvolve como um memorando perceptual - como os que Eduardo Kohn encontrou entre os Ávila Runa do Equador. Nesses memorandos "[...] não se trata apenas de recriar para o ouvinte uma série de episódios, mas de fazer uma transcrição visual e auditiva da experiência" (Carneiro da Cunha, 2009, p. 366). Na sua Crônica dos Índios Guayaki, Clastres também destaca o comportamento cuidadoso do caçador, que entrega a caça a outras pessoas da aldeia. ${ }^{24} \mathrm{O}$ caçador age com extrema polidez em relação ao animal abatido, pois "[...] caçar não é simplesmente matar animais, é contrair uma dívida a seu respeito". (Clastres, [1972] 1995, p. 100)

Os animais da floresta - porém, não todos - têm seus donos, anidawa. No cotidiano suruwaha, a expressão anidawa se aplica a quem cria, produz (uma casa, uma zarabatana, uma roça...) e aos promotores e patrocinadores de atividades coletivas, como caçadas e pescarias. Mais do que um sentido de propriedade, a noção nativa de domínio, expressada através do termo anidawa, caracteriza o poder criativo ${ }^{25}$. $\mathrm{O}$ anidawa da roça escolhe o local de abertura da mata, derruba e planta. O anidawa de uma pescaria ou de uma caçada escolhe o igarapé ou a região de caça, organiza o acampamento, providencia o timbó (no caso de pescaria) e a mandioca fermentada para o conjunto do grupo, nas refeições coletivas. O dono de uma casa, uda, escolhe também a sua localização e assume o processo integralmente (seleção, preparo, carregamento e instalação dos esteios, caibros e linhas que formam a estrutura da maloca; confecção da cobertura de palha de caranaí): ele precisará da colaboração de outras pessoas em diversas tarefas, mas para isso manterá uma relação de troca e retribuição com aqueles que o ajudaram. A criatividade e o poder gerativo parecem apontar o sentido de domínio no pensamento suruwaha.

Em que consistiria, então, a relação dos animais com seus anidawa? Numa rodada de tabaco, à noite, Xamtiria e Gamuki me 
contaram que nem todos os animais possuem um "dono". Antas, macacos-barrigudos, jacarés, sucurijus, magoaris têm sim um anidawa. Xamtiria identifica alguns dos ancestrais: Mujawi é anidawa das antas; Baka, dos jacarés; Hawawi, dos magoaris; e Imidi, dos queixadas. Tucanos e araras, por exemplo, não aparecem como relacionados com um dono, e sim com os espíritos-cantores, kurimia. Não estou seguro que, para os Suruwaha, a relação de englobamento "chefe/corpo/dono", ao estilo do warah entre os Kanamari (Costa, 2007, p. 46), defina o vínculo entre os anidawa e o respectivo coletivo animal. A relação de maestria-domínio entre o anidawa e os animais da 'espécie' implica certamente uma dinâmica diferenciante.

Nesse sentido, mais do que um representante (i.e., alguém que está no lugar de), o chefe-mestre é a forma pela qual um coletivo se constitui enquanto imagem; é a forma de apresentação de uma singularidade para outros (Fausto, 2008, p. 334)

A conexão parece estar estabelecida no marco de uma relação transformacional, que conecta a pessoa geradora com o animal a partir de um evento xamânico de natureza conflituosa. Nesse sentido, Baka - anidawa do jacaré-açu - não constitui um "hiper-jacaré" (no sentido de representante por antonomásia da 'espécie'), e sim um antecessor, aliás, o antecedente humano que, transformado, deu origem aos jacarés com sua forma-corpo atual. E é a mediação xamânica a que atualiza o termo final da transformação.

A passagem do contínuo ao discreto se desenvolve como multiplicação das multiplicações, de diferenciação extensiva, com movimentos que podem ampliar a condição de pessoa a espécies animais, ou negá-la a (não) humanos inimigos e estrangeiros. "A semelhança ou a congeneridade surgem por suspensão deliberada, socialmente produzida, de uma diferença predatória dada; não são anteriores a ela" (Viveiros de Castro, 2010, p. 38). Esta diferença predatória que fundamenta a socialidade cósmica dá origem, no pensamento dos Suruwaha, a uma atividade classificatória dos animais que, como veremos, tem mais a ver com posições relacionais do que com um sistema 
taxonômico de caráter "etnocientífico". Nesse sentido, os Suruwaha situam alguns animais como pertencentes à categoria igiaty e outros à categoria zamatymyru. ${ }^{26}$ Kroemer (1994, p. 90) interpreta este esquema classificatório a partir do contraste entre animais arborícolas (igiaty, que compreenderia aves e primatas, no dossel da floresta) e animais terrestres (zamatymyru). Porém, sugere-se como hipótese outro critério para estabelecer o contraste classificatório: a partir, precisamente, da condição relacional de caça ou de adoção. Erikson, no cenário do vale do Javari, encontra na concepção mais uma distinção entre os animais de caça e os xerimbabos, que se constituem como "contrapeso semântico da caça" (Erikson, 2012, p. 20; Erikson, 1987): estes são submetidos a um processo de "desanimalização", que oculta sua origem silvestre e os introduz num processo de comensalidade ou "alimentação cultural" (Erikson, 2012, p. 22). Mais ainda, eles se constituem numa extensão do corpo dos seus donos.

Para os Suruwaha, zamatymyru ("coisas saborosas") se refere aos animais em que se destaca uma relação de predação (aqueles que são procurados pelos caçadores como suas presas, bahi), enquanto igiaty ressalta a condição de adoção (os animais passíveis de familiarização, wild pets). Não quer dizer, em absoluto, que os igiaty não sejam considerados comestíveis ou inclusive apetecíveis (eles de fato fazem parte da alimentação cotidiana dos Suruwaha), ou que filhotes de zamatymyru capturados nas caçadas não sejam familiarizados no espaço doméstico ${ }^{27}$. Trata-se de posições relacionais e, por isso, mesmo, variáveis - o que implica na possibilidade da reversão. Dependendo da situação, as posições se transmutam: a categorização permite modificações - há, porém, posições mais claramente definidas, como o estatuto tipicamente predatório do jaguar ou da sucuriju, ou o estatuto de "hiperpresas" que caracteriza aos peixes (Aparicio, 2014a, p. 169). Para um caçador suruwaha, antas, queixadas e macacos-barrigudos constituem sem dúvida os zamatymyru mais almejados. Ao mesmo tempo, mutuns, jacus e cutiaras, por exemplo, habitualmente denotam uma condição de igiaty. O que os Suruwaha põem em destaque é a ênfase no contraste qualitativo entre os seres 'predáveis' (os zama- 
tymyru) e os seres 'adotáveis' (os igiaty), o que instaura uma relação baseada em diferenças de socialidade. Isso remete a uma proximidade com o sistema de classificação paumari, que opõe os ighita ("aqueles imediatamente considerados com inofensivos para os homens" e que "designa igualmente o animal de estimação, as presas domesticadas assim como alguns animais domésticos introduzidos recentemente pelos missionários") aos tapo'ija ("que se encontram em uma posição de agressor ou devorador") (Bonilla, 2007, p. 262). É significativo perceber que a condição de adoção (ighita) serve aos Paumari de referência para conceber suas próprias relações de alteridade, mas numa peculiar dinâmica de oscilação, segundo a qual "[...] a arma predatória dos Paumari é sem dúvida sua capacidade de sujeição, que para se realizar obriga o interlocutor colocado em posição de dominação a apiedar-se deles e a adotá-los". (Bonilla, 2013, p. 18)

Para os Deni (habitantes do rio Cuniuá, assim como os Suruwaha), todos os animais com exceção dos peixes podem ser englobados na categoria bani. Nos Jarawara, "[...] bani quer dizer literalmente caça, podendo significar também animal, em geral sem especificar qual. Mas não seria qualquer animal e sim um animal considerado boa caça" (Maizza, 2012, p. 48). O termo assemelha com o suruwaha bahi, que significa 'presa', 'vítima', 'produto da caça'. Contudo, “[...] diferente dos Jarawara, bani não corresponde apenas à posição de presa, pois os Deni atribuem para a onça o nome bani zavirivi (bani malhado), que seria utilizado antigamente, ou seja, quando as onças ainda eram predadores de humanos" (Florido, 2013, p. 155-156). De todo modo, para além das variantes identificáveis nesses cenários arawa, parece que há um paradigma amazônico bastante estendido em que a condição 'animal' exprime os significados de 'presa', 'caça' ou 'vítima', e que Viveiros de Castro (2006, p. 320) aponta como polo de oposição à condição de 'espíritos', como "seres supremamente incomestíveis".

Essa diferença de posições é relevante inclusive na concepção nativa de humanidade, como mostra a narrativa sobre os irmãos-humanos ancestrais e sua relação com os jaguares-demiurgos "fundadores da cultura" (Aparicio, 2014a, p. 107). No mito suruwaha, Ajiaji e Wanykaxiri, filhos dos humanos ${ }^{28}$, são capturados pelo casal de jagua- 
res, Ajimarihi e Jumanihia, que os criam na sua casa e transmitem a eles os saberes necessários para a fabricação do arco, das flechas e do curare, da rede, da casa e da cerâmica. A narrativa está permeada por elementos que expressam movimentos ambíguos de humanização e de jaguarificação nos dois irmãos. Quando eles descobrem a intenção que os avós-onças têm de devorá-los, irrompe uma transmutação dos pontos de vista e as posições se alteram ${ }^{29}$. A relação estabelecida a partir da figura dos avós adotivos-jaguares-predadores sobre os netos adotivos-humanos-presas inverte-se num desfecho predador dos irmãos sobre os jaguares. O caráter relacional e instável das posições de predador e presa abre a possibilidade da inversão de perspectivas. O vínculo de adoção que as onças estabeleceram com os humanos é ambíguo e inconstante, ele se constitui como obviação de um substrato de inimizade (Fausto, 2008, p. 352) e de perigo permanente. A ideologia suruwaha parece sustentar uma atitude proativa dos humanos, que movimenta uma espécie de paradoxo segundo o qual a "adoção predatória" dos jaguares sobre os humanos deriva em contrapredação, como atitude reversa destes sobre os jaguares.

\section{Notas}

1 Este artigo tem como base um capítulo revisado da minha dissertação de mestrado em Antropologia Social na Universidade Federal do Amazonas (Aparicio, 2014a), elaborada sob a orientação de Gilton Mendes dos Santos e Márcio F. Silva. Para o desenvolvimento da pesquisa contei com recursos da Fundação de Amparo à Pesquisa do Estado do Amazonas.

2 Os Suruwaha atuais se formaram a partir da convergência de diversos coletivos dawa (Aparicio, 2013, p. 257) que habitavam a região dos rios Cuniuá e Riozinho, subafluentes do Purus, no Amazonas, em decorrência dos impactos originados pelo avanço das frentes extrativistas na primeira metade do século XX. Hoje ocupam o entorno de um pequeno igarapé, Jukihi, no interflúvio Purus-Juruá, fazendo parte do "corredor Arawa" junto com os Deni, Kamadeni, Banawa, Hi Merimã, Jarawara, Jamamadi e Paumari do rio Tapauá. A terra indígena Zuruaha foi demarcada em 1987 e homologada em 1991. A população atual é de aproximadamente 140 pessoas.

3 Parece pertinente aderir à posição de Viveiros de Castro (2006, p. 327), quando afirma que "[...] na maioria dos casos amazônicos, senão em todos, não existe noção submersa que signifique 'animal não-humano'. Naturalmente, esta afirmação pode ser desmentida a qualquer momento".

4 Os mitos que constam nas próximas páginas foram narrados pelo jovem Ania, na casa de Ikiji, entre outubro e novembro de 1997. O xamã Axa, pai de Ania, contribuiu com detalhamentos e sugestões aos relatos expostos, que foram registrados em língua Suruwaha, e que traduzi ao português na versão aqui apresentada. 
5 Dado que a larva da mosca-varejeira (kurazuwy) se desenvolve em carnes em decomposição, a presença dela dá a entender a Buraku que seu pai está morto.

6 Alguns elementos destes mitos suruwaha mostram uma heterogeneidade prévia dos animais ex-humanos, jadawakyba. Como afirma Calavia ao analisar a mitologia kaxinawa, "[...] o motivo da transformação é, em todos os casos, um certo hiato corporal que já existe entre o protagonista e o seu grupo [...]. Os artifícios aplicados no corpo constroem a partir de uma prévia diversidade de naturezas". (Calavia, 2004, p. 243)

7 Os Jarawara narram uma variante deste mito, "Bakayona": cfr. Vogel, disponível em: <http://www-01.sil.org/americas/brasil/publcns/ling/JATxtsPt.html>.

8 Para os Suruwaha, o arco-íris é o caminho póstumo dos mortos por veneno de serpente.

9 Veja-se, nesse sentido, a proximidade com a categoria haytekéra, conforme descrito por Garcia (2010, p. 91) nos Awa.

${ }^{10}$ Contudo, deve ser considerada a não equivalência de significado entre os conceitos nativos karuji e anidawa. Certamente, às pessoas destacadas pela sua proatividade é atribuída uma especial vitalidade, o que faz com que as suas iniciativas - promover caçadas, pescarias, edificar casas, abrir roçados - inspirem também a vida coletiva. Se karuji pode remeter a um sentido de liderança, anidawa expressa o domínio enquanto habilidade criativa. E de modo algum quer dizer que a pessoa com liderança mantenha uma relação de domínio sobre o conjunto do grupo.

${ }^{11}$ Literalmente, "amarrar o suspensório peniano", ação que define a iniciação dos jovens.

12 Hamy foi a principal liderança suruwaha durante os anos '80-'90; faleceu por envenenamento com timbó em 1999. Excelente diplomata nas relações com os novos atores indigenistas e missionários, destacou também internamente pela sua proatividade e capacidade de gerar consenso. Foi, para os Suruwaha, o melhor caçador de antas (mahuny agy) e o dono (anidawa) das principais pescarias e caçadas coletivas.

${ }^{13}$ Huriatini é uma buzina em formato cônico, feita com embira, que os Suruwaha utilizam para avisar às pessoas que permaneceram na casa ou nos acampamentos do sucesso no abate de um animal durante a caçada.

14 Na distribuição da carne de caça, a função do nauhyru consiste em retalhar, cozinhar e distribuir a carne. Na verdade, o dono do animal abatido não é o caçador, mas o nauhyru. Entre os Suruwaha não é aceito que o caçador assuma o preparo dos animais de grande porte abatidos por ele próprio.

15 A elaboração das bebidas fermentadas, e tudo aquilo associado à sua produção (como a confecção da cerâmica), constitui "[...] o verdadeiro correlato da atividade cinegética e guerreira masculina". (Viveiros de Castro, 1992, p. XVII)

16 A prática de envenenamento com timbó a partir de situações de conflito está firmemente consolidada entre os Suruwaha das últimas gerações, até o ponto de constituir $86 \%$ das causae mortis entre os jovens e adultos. Para uma análise etnográfica do envenenamento suruwaha. (Aparicio, 2014a, p. 140-170)

17 Gaha tymyri ("imitar os macacos-barrigudos") é um ritual realizado comumente de manhã, após as festas de canto noturno, kawajumari, e dos ritos de iniciação dos jovens wasi. Consiste numa luta entre afins e consanguíneos dos jovens wasi. Nela os participantes, enfeitados com palmas de tumasiki, imitam o comportamento dos macacos-barrigudos e desenvolvem um confronto ritual, de caráter lúdico. 
18 Da mesma forma, entre os Katukina do Biá (com o termo jan) e entre os Awa (Garcia, 2010, p. 270)

19 Assim como nos Deni (Florido, 2013, p. 114). A única restrição que observei entre os Suruwaha diz respeito ao peixe aruanã ( $a b a$ mazaru) que, como o seu nome nativo indica, está ligado ao feitiço/morte (mazaru). Sobre o tema das ausências de tabu na caça em povos amazônicos, e sobre o caráter de abundância e não de escassez do trekking. (Fausto, 2001, p. 153)

${ }^{20}$ Diversos cenários das Terras Baixas sul-americanas manifestam esta conexão entre flechas e serpentes, que possuem uma identidade comum a partir do veneno. Para os Mamaindê (Nambikwara) do vale do Guaporé, "[...] as flechas envenenadas usadas para caçar se transformam em cobras venenosas" (Miller, 2009, p. 67). Nos Karitiana (grupo de língua Ariken no vale do rio Candeias, em Rondônia), “o veneno conecta flechas e serpentes: diz-se que as [flechas] bokore têm 'o sentido da cobra', isto é, parecem cobras", e os mitos narram este vínculo (Vander Velden 2011 : 240). Os Suruwaha açoitam com flechas as pernas dos jovens, para protegê-los do risco de picadas de cobra. De modo análogo, entre os Xerente, no cerrado do vale do Tocantins, está presente o hábito de açoitar os jovens com caudas de serpente, para que eles se tornem mais fortes (Valéria Melo, comunicação pessoal).

${ }^{21}$ Marcelo Florido (comunicação pessoal).

22 Para os Suruwaha, bater com o cotovelo no corpo de outra pessoa (seja voluntariamente ou não) produz a transmissão do feitiço, mazaru. (Aparicio, 2014b)

23 A análise de Descola do contexto ashuar parece compatível para caracterizar também as atitudes suruwaha. "Para poder caçar eficazmente, todo homem deve manter relações de boa inteligência com a caça e com os espíritos que a controlam, segundo um princípio de conivência que atua de modo mais ou menos explícito em todas as sociedades cinegéticas ameríndias [...]. A caçada é uma prática lícita, mas as 'mães da caça' estão aí para lembrar permanentemente que ela não pode ser um ato gratuito". (Descola, [1987] 1996, p. 348-350)

24 Agradeço a Tânia Stolze Lima pela pista que apontou a semelhança entre as atitudes dos caçadores suruwaha e aché.

25 Na minha convivência com os Suruwaha, o diálogo em relação aos meus objetos "de branco" (a lanterna, a mochila, a rede, o gravador, o creme dental, etc.) refletia sempre o conflito entre nosso conceito de "dono/proprietário" e o conceito suruwaha de "anidawa/criador". Quando me perguntavam, por exemplo, se a lanterna era minha, causava estranhamento o fato de eu não saber fabricá-la. Uma pessoa é dono de uma zarabatana ou de uma casa basicamente porque sabe produzi-las. Num sentido muito semelhante, Erikson conecta as noções de ownership e craftsmanship entre os Matis do rio Javari (2009, p. 175). Sobre os Marubo, Cesarino afirma que “[...] [t]odo dono é também um shovimaivo, algo como o 'fazedor' ou o criador': o fazedor de uma canoa, de uma casa, de um colar". (2010, p. 167)

${ }^{26}$ Não creio que a nossa categoria 'animal' tenha um táxon equivalente na concepção suruwaha. A rigor, as categorias zamatymyru e igiaty (e outras como aba, referida aos que habitam igarapés, rios e lagos, e igiatykyry, que designa os pequenos pássaros da floresta) não constituem subdivisões de uma categoria maior, mas maneiras de expressar a variedade de condição relacional no âmbito desta economia simbólica da predação.

27 Sobre este tema num outro cenário etnográfico. (Fausto, 2000, p. 937; 2001, p. 413). No cenário dos povos de língua Arawa, Katukina e Pano, cfr. a excelente análise 
dos pet vocatives desenvolvida pelos linguistas Dienst e Fleck (2009). No artigo, eles confrontam a terminologia suruwaha com as terminologias jarawara e paumari.

${ }^{28}$ Na narrativa suruwaha, os irmãos Ajiaji e Wanykaxiri são filhos de Tiawakuru (nome do pássaro conhecido regionalmente como "bico-de-brasa"), que expressa a posição-humano (jadawa) em contraste com a posição-jaguar de Ajimarihi (literalmente, o "avô-onça") e sua esposa Jumanihia.

29 Esta alternância posicional é identificada por Viveiros de Castro como característica das cosmologias amazônicas, nas quais “[o] discurso mítico descreve a instantânea perda de importância dos fluxos pré-cosmológicos quando entra no processo cosmológico; daí em diante, as dimensões felinas e humanas dos jaguares (e as dos humanos) funcionarão alternando-se como potenciais figura e fundo uma da outra. A partir daí, a transparência original ou complicatio infinita se bifurca ou se explica na invisibilidade (das almas humanas e dos espíritos animais) e na opacidade (do corpo humano e das roupagens somáticas animais) que marcam a constituição do todos os seres mundanos". (Viveiros de Castro, 2010, p. 46-47)

\section{Referências}

APARICIO, Miguel. Os Suruwaha e sua rede de relações. Uma hipótese sobre localidades e coletivos Arawa. In: AMOROSO, M.; MENDES DOS SANTOS, G. (Org.). Paisagens Ameríndias: lugares, circuitos e modos de vida na Amazônia. São Paulo: Terceiro Nome, 2013. p. 247-273.

APARICIO, Miguel. Presas do timbó. Cosmopolítica e transformações suruwaha. Dissertação Mestrado em Antropologia Social - Universidade Federal do Amazonas, Manaus, 2014a.

APARICIO, Miguel. Xamanismo suruwaha e transformações. Amazônica - Revista de Antropologia, Belém: Universidade Federal do Pará, v. 6, n. 2, p. 503-525, 2014b.

BONILLA, L. Oiara. Des proies si désirables: soumisson et prédation pour les Paumari d'Amazonie brésilienne. Tese Doutorado em Antropologia Social - École des Hautes Études en Sciences Sociales, Paris, 2007.

BONILLA, L. Oiara. Parasitismo e sujeição: modos de predação paumari, 2013. (no prelo)

CALAVIA SÁEZ, Oscar. Moinhos de vento e varas de queixadas.

O perspectivismo e a economia do pensamento. Mana. Estudos de

Antropologia Social, Rio de Janeiro: Museu Nacional, UFRJ, v. 10, n. 2, p. 227-256, 2004.

CARNEIRO DA CUNHA, Manuela. 'Cultura' e cultura: conhecimentos intelectuais e direitos tradicionais. In: CARNEIRO DA CUNHA, M. Cultura com Aspas. São Paulo: Cosac Naify, 2009. p. 311-373. 
CESARINO, Pedro. Donos e Duplos: relações de conhecimento, propriedade e autoria entre os Marubo. Revista de Antropologia, São Paulo: USP, v. 53, n. 1, p. 147-197, 2010.

CLASTRES, Pierre. Crônica dos Índios Guayaki: o que sabem os Aché, caçadores nômades do Paraguai. Rio de Janeiro: Editora 34, [1972] 1995. COSTA, Luiz A. As Faces do Jaguar: parentesco, história e mitologia entre os Kanamari da Amazônia Ocidental. Tese Doutorado em Antropologia Social - Universidade Federal do Rio de Janeiro, Rio de Janeiro, 2007.

DESCOLA, Philippe. La selva culta: simbolismo y praxis en la ecología de los Achuar. Quito: Abya Yala, [1987] 1996.

DIENST, Stefan; FLECK, David W. Pet Vocatives in Southwestern Amazonia. Anthropological Linguistics, University of Nebraska Press, v. 51, n. 3-4, p. 209-243, 2009.

ERIKSON, Philippe. De l'apprivoisement à l'approvisionnement. Chasse, alliance et familiarisation en Amazonie amérindienne. Theorie et Culture, Paris, n. 9, p. 105-140, 1987.

ERIKSON, Philippe. Obedient Things. Reflections on the Matis Theory of Materiality. In: SANTOS-GRANERO, Fernando (Ed.). The Occult Life of Things. Native Amazonian Theories of Materiality and Personhood. Tucson: The University of Arizona Press, 2009.

ERIKSON, Philippe. Animais demais. Os xerimbabos no espaço doméstico matis (Amazonas). Anuário Antropológico, Brasília: UnB, v. 2011 II/2012, p. 15-32, 2012.

FAUSTO, Carlos. Of Enemies and Pets: Warfare and Shamanism in Amazonia. American Ethnologist, American Anthropological Association, USA, v. 26, n. 4, p. 933-956, 2000.

FAUSTO, Carlos. Inimigos fiéis: história, guerra e xamanismo na Amazônia. São Paulo: EDUSP, 2001.

FAUSTO, Carlos. Donos demais: Maestria e Domínio na Amazônia. Mana. Estudos de Antropologia Social, Rio de Janeiro: Museu Nacional, UFRJ, v. 14, n.2, p. 329-366, 2008.

FLORIDO, Marcelo. Os Deni do Cuniuá: um estudo do parentesco. Tese Doutorado em Antropologia Social - Universidade de São Paulo, São Paulo, 2013.

GARCIA, Uirá F. Karawara. A caça e o mundo dos Awá-Guajá. Tese Doutorado em Antropologia Social - Universidade de São Paulo, São Paulo, 2010 . 
GARCIA, Uirá F. O funeral do caçador: caça e perigo na Amazônia. Anuário Antropológico, Brasília: UnB, v. 2011-II/2012, p. 33-55, 2012. GONÇALVES, Marco A. O mundo inacabado: ação e criação em uma cosmologia amazônica. Etnografia pirahã. Rio de Janeiro: Editora UFRJ, 2001.

GOW, Peter. An Amazonian Myth and Its History. Oxford: Oxford University Press, 2001.

KOHN, Eduardo. How Forests Think: toward an Anthropology beyond the Human. Berkeley - Los Angeles - London: University of California Press, 2013.

KROEMER, Gunter. Kunahã Made: o Povo do Veneno. Sociedade e cultura do povo Zuruahá. Belém: Edições Mensageiro, 1994.

MAIZZA, Fabiana. Cosmografia de um mundo perigoso: espaço e relações de afinidade entre os Jarawara da Amazônia. São Paulo: Nankin Editorial/Edusp, 2012.

MILLER, Joana. Things as Persons. Body Ornaments and Alterity among the Mamaindê (Nambikwara). In: SANTOS-GRANERO, Fernando (Ed.). The Occult Life of Things: Native Amazonian Theories of Materiality and Personhood. Tucson: The University of Arizona Press, 2009.

MENDES DOS SANTOS, Gilton. Da cultura à natureza: um estudo do cosmos e da ecologia dos Enawene-Nawe. Tese Doutorado em Antropologia Social - Universidade de São Paulo, São Paulo, 2006.

TEIXEIRA-PINTO, Marnio. Ieipari: Sacrifício e Vida Social entre os índios Arara (Caribe). São Paulo: Editora Hucitec - ANPOCS, 1997.

VANDER VELDEN, Felipe F. As flechas perigosas: notas sobre uma perspectiva indígena da circulação mercantil de artefatos. Revista de Antropologia, São Paulo: USP, v. 54, n. 1, p. 231-267, 2011.

VIVEIROS DE CASTRO, Eduardo. Apresentação. In: VILAÇA, Aparecida. Comendo como gente: formas de canibalismo Wari. Rio de Janeiro: Editora UFRJ, p. I-XVI, 1992.

VIVEIROS DE CASTRO, Eduardo. A floresta de cristal. Notas sobre a ontologia dos espíritos amazônicos. Cadernos de Campo, São Paulo: USP, n. 14/15, p. 319-338, 2006.

VIVEIROS DE CASTRO, Eduardo. Metafísicas caníbales. Buenos Aires: Katz Editores, 2010. 
VOGEL, Alan. Textos Jarawara Interlineares. [2014]. Disponível em: $<$ http://www-01.sil.org/americas/brasil/publcns/ling/JATxtsPt.html $>$. Acesso em: 26 fev. 2014.

Recebido em 27/3/2014

Aceito em 24/1 1/2014 